\title{
Description of Three New Species of the Genus Peptostreptococcus from Human Clinical Specimens: Peptostreptococcus harei sp. nov., Peptostreptococcus ivorii sp. nov., and Peptostreptococcus octavius sp. nov.
}

\author{
D. A. MURDOCH ${ }^{1 *}$ M. D. COLLINS ${ }^{2}$ A. WILLEMS ${ }^{2}$ J. M. HARDIE,${ }^{3}$ \\ K. A. YOUNG ${ }^{3}$ AND J. T. MAGEE ${ }^{4}$ \\ Department of Medical Microbiology, Southmead Health Services NHS Trust, Bristol BS10 5NB, ${ }^{1}$ \\ Department of Microbiology, Institute of Food Research, Reading RG6 6BZ, ${ }^{2}$ Department \\ of Oral Microbiology, St. Bartholomew's and the Royal London School of Medicine \\ and Dentistry, London E1 2AD, ${ }^{3}$ and Public Health Laboratory, University \\ Hospital of Wales, Cardiff CF4 $4 X W{ }^{4}$ United Kingdom
}

\begin{abstract}
In a previous investigation of the laboratory identification of clinical strains of the genus Peptostreptococcus, several isolates were found to be atypical. In this study, we further examined these strains by using both phenotypic and genotypic methods. Based on our findings, we describe the following three new species of the genus Peptostreptococcus from human clinical specimens: Peptostreptococcus harei, whose type strain is DSM 10020 (isolated from a sacral sore); Peptostreptococcus ivorii, whose type strain is DSM 10022 (isolated from a leg ulcer); and Peptostreptococcus octavius, whose type strain is NCTC 9810 (isolated from nasal flora). An analysis of their 16S rRNA gene sequences indicated that all three species are related to Clostridium cluster XIII, which includes most species of the genus Peptostreptococcus. The phenotypic characteristics of the new species are described.
\end{abstract}

The genus Peptostreptococcus as currently constituted consists of a group of obligately anaerobic gram-positive cocci which is phenotypically very diverse $(2,10,19)$. In addition to considerable metabolic diversity, members of the genus have been shown by nucleic acid analysis to be phylogenetically heterogeneous $(2,11,15,22)$. In particular, Peptostreptococcus anaerobius, the type species of the genus Peptostreptococcus, is phylogenetically far removed from other peptostreptococci $(11,22)$ and exhibits a close affinity with certain clostridial species (Clostridium rRNA cluster XI, as described by Collins et al. [2]). Peptostreptococcus productus has been shown to be a close phylogenetic relative of Clostridium coccoides and Streptococcus hansenii (Clostridium rRNA cluster XIVa [2]), whereas the majority of peptostreptococcal species form a phylogenetically distinct group closely related to Helcococcus kunzii (Clostridium rRNA cluster XIII [2]). At present, the genus Peptostreptococcus comprises 13 species (5), but unnamed groups of strains which may constitute additional species have been described $(15,19)$; the species Peptostreptococcus asaccharolyticus and Peptostreptococcus prevotii are recognized as genetically heterogeneous taxa $(5,9,10,14,19,23)$.

In a study of more than 250 human clinical and reference strains of peptostreptococci, approximately $20 \%$ of the organisms could not be identified to the species level (19). When the whole-cell compositions of 127 peptostreptococci, most of which were from this collection, were investigated by pyrolysis mass spectrometry (PyMS), the results confirmed the presence of several unrecognized taxa (18). One group corresponded to Hare group VIII (24), which has not to date been validly named. In this study, PyMS was used to select seven representative strains from Hare group VIII and two other previously undescribed groups. We performed additional biochemical in-

\footnotetext{
* Corresponding author. Phone: 00441179 595651. Fax: 00441179 593154.
}

vestigations on these strains, compared their phenotypic characteristics with the phenotypic characteristics of appropriate type strains of species of the genus Peptostreptococcus, and determined their phylogenetic relationships by performing a 16S rRNA gene sequence analysis. On the basis of phenotypic and genotypic criteria, the following three new species are proposed: Peptostreptococcus harei, Peptostreptococcus ivorii, and Peptostreptococcus octavius.

\section{MATERIALS AND METHODS}

Investigation of whole-cell compositions by PyMS. The 127 strains investigated by PyMS comprised 101 clinical strains and 26 reference strains included for comparison. Ninety clinical strains were selected from a previously described collection $(19,20)$ of 256 strains from St. Bartholomew's Hospital in London, United Kingdom; these strains were chosen to represent the full range from biochemically typical strains to highly atypical strains. They were supplemented with 11 strains isolated at Southmead Hospital in Bristol, United Kingdom; 7 of these strains resembled Peptostreptococcus tetradius, 1 resembled Peptostreptococcus indolicus, and 3 resembled Peptostreptococcus hydrogenalis. The reference strains were acquired recently from appropriate reference collections and included the type strains of Peptococcus niger and all recognized species of the genus Peptostreptococcus. The methods used for PyMS have been described elsewhere $(8,16,17)$. Briefly, growth from blind-coded cultures of the 127 strains was sampled in quadruplicate and placed on pyrolysis foils (Horizon Instruments, Heathfield, United Kingdom). Each foil was processed in a PyMS model $200 \mathrm{X}$ pyrolysis mass spectrometer (Horizon Instruments), in which the foil and specimen were heated in a vacuum to $530^{\circ} \mathrm{C}$ for $4 \mathrm{~s}$. Volatile products were subjected to low-energy electron impact ionization $(35 \mathrm{eV})$, and the ions produced were separated and quantified with a quadrupole mass spectrometer. The spectra produced were recorded, and mean strain spectra were compared statistically by using the Discriminant Analysis procedure of the SPSS-PC suite (1) The resulting dissimilarity matrix was visualized as a dendrogram by using the Clustan 2-PC suite (25)

Biochemical and physiological characterization. Seven strains were selected for further biochemical and genetic analysis (Table 1). The strains were first characterized by previously described methods (19). Briefly, we determined the cellular and colonial morphology, the preformed enzyme profile (PEP) with the ATB 32 A commercial system (API-Biomerieux, Basingstoke, United Kingdom), and the volatile fatty acid (VFA) profile by using gas-liquid chromatography (10, 19). The ATB 32A kit was used to detect production of indole, urease, alkaline phosphatase (ALP), and arginine dihydrolase (ADH). Tests for carbohydrate fermentation (acid production) were then performed in 3-ml volumes of Fastid- 
TABLE 1. Peptostreptococcus strains used in this study

\begin{tabular}{lll}
\hline \multicolumn{1}{c}{ Species or group } & \multicolumn{1}{c}{ Strain $^{a}$} & \multicolumn{1}{c}{ Source } \\
\hline P. asaccharolyticus & NCTC $11461^{\mathrm{T}}$ & Not recorded \\
P. indolicus & NCTC $11088^{\mathrm{T}}$ & Bovine summer mastitis \\
P. prevotii & NCTC $11806^{\mathrm{T}}$ & Plasma \\
P. tetradius & DSM $2951^{\mathrm{T}}$ & Vaginal discharge \\
P. hydrogenalis & DSM $7454^{\mathrm{T}}$ & Vaginal discharge \\
P. lacrimalis & DSM $7455^{\mathrm{T}}$ & Discharge from eye \\
P. lactolyticus & DSM $7456^{\mathrm{T}}$ & Vaginal discharge \\
P. vaginalis & DSM $7457^{\mathrm{T}}$ & Ovarian abscess \\
Peptostreptococcus sp. & DSM $10020^{\mathrm{T}}$ & Pus from sacral sore \\
Peptostreptococcus sp. & DSM 10021 & Pus from peritoneal cavity \\
Peptostreptococcus sp. & DSM $10022^{\mathrm{T}}$ & Leg ulcer \\
Peptostreptococcus sp. & DSM 10023 & Swab from abdominal cavity \\
Hare group VIII & NCTC $9810^{\mathrm{T}}$ & Nasal flora \\
Hare group VIII & NCTC 9820 & Nasal flora \\
Peptostreptococcus sp. & DSM 10024 & Antral washout, maxillary sinusitis \\
\hline
\end{tabular}

a NCTC, National Collection of Type Cultures, London, United Kingdom; DSM, Deutsche Sammlung von Mikroorganismen und Zellkulturen GmbH, Braunschweig, Germany.

ious Anaerobic Broth (FAB) (LabM, Bury, United Kingdom) containing $0.1 \%$ Tween 80 and a filter-sterilized solution of the test carbohydrate (Sigma, Poole, United Kingdom) at a concentration of $1 \%(\mathrm{wt} / \mathrm{vol})$. The organisms were first grown in $3-\mathrm{ml}$ portions of $\mathrm{FAB}$ containing $0.1 \%$ Tween 80 anaerobically at $37^{\circ} \mathrm{C}$ for $48 \mathrm{~h}$ to produce turbid suspensions. Then $150-\mu \mathrm{l}$ portions of the suspensions were used to inoculate preparations containing each of the test carbohydrates. The cultures were incubated anaerobically for $48 \mathrm{~h}$ or until no obvious increase in growth (assessed visually as turbidity) had occurred for $24 \mathrm{~h}$. All tests were performed in duplicate. The $\mathrm{pH}$ of each culture was measured with a Corning $\mathrm{pH}$ meter (model 220), and the change in $\mathrm{pH}$ was compared with the change in $\mathrm{pH}$ of an inoculated, incubated culture in FAB containing $0.1 \%$ Tween 80 but no added carbohydrate. All of the strains tested produced heavy turbid suspensions in broth after a maximum incubation period of $72 \mathrm{~h}$. The presence of coagulase activity was determined by using rabbit plasma (Difco, West Molesey, United Kingdom). A heavy suspension of a 48-h culture harvested from a Fastidious Anaerobic Agar (LabM) purity plate was prepared in $0.2 \mathrm{ml}$ of sterile distilled water. Then $0.5 \mathrm{ml}$ of reconstituted rabbit plasma was added, and the mixture was incubated at $37^{\circ} \mathrm{C}$ for $4 \mathrm{~h}$. A positive reaction was a reaction in which the plasma was converted into a stiff gel. All negative test preparations were left at room temperature overnight and reexamined. P. indolicus NCTC $11088^{\mathrm{T}}$ was used as a positive control, and a known coagulase-negative strain and uninoculated plasma were used as negative controls. Nitrate reduction was determined by using 3-ml portions of indole-nitrate medium (Becton Dickinson, Cockeysville, Md.) containing $0.1 \%$ ( $\mathrm{vol} / \mathrm{vol}$ ) Tween 80 that were incubated anaerobically at $37^{\circ} \mathrm{C}$ for $48 \mathrm{~h}(3)$; known positive and negative strains were used as controls.

Determination of base composition of DNA. Cells grown anaerobically in FAB were harvested by centrifugation, and the cell pellet was washed in TES buffer (0.05 M Tris-HCl, $0.05 \mathrm{M} \mathrm{NaCl}, 0.005 \mathrm{M}$ EDTA), pH 8.0. Cell lysis, DNA extraction, and purification were performed by a modified method based on the method of Garvie (7); 1,500 U achromopeptidase (Wako Pure Chemical Industries, Ltd., Osaka, Japan) per $\mathrm{ml}$ of cell suspension was added, but the sodium deoxycholate treatment was omitted. Base compositions were determined by thermal denaturation in $1 \times \mathrm{SSC}(0.15 \mathrm{M} \mathrm{NaCl}$ plus $0.015 \mathrm{M}$ trisodium citrate, $\mathrm{pH} 7.0)$ performed with a model 240 spectrophotometer (Gilford, Oberlin, Ohio) at $260 \mathrm{~nm}$ and by using a Gilford model 2527 thermoprogrammer (heating rate, $1{ }^{\circ} \mathrm{C} / \mathrm{min}$ ). The $\mathrm{G}+\mathrm{C}$ content was calculated by the method of Owen and Hill (21).

Determination of $16 S$ rRNA gene sequence. Samples of DNA were prepared from seven selected strains by using the method of Lawson et al. (13). The 16S rRNA genes were amplified by PCR by using conserved primers pA (5'-AGAG TTTGATCCTGGCTCAG; positions 8 to 27 [Escherichia coli numbering]) and $\mathrm{pH}^{*}$ (5'-AAGGAGGTGATCCAGCCGCA; positions 1541 to 1522) as described previously (12). The PCR products were purified by using a Prep-A-Gene kit (Bio-Rad, Hercules, Calif.) according to the manufacturer's instructions and were sequenced directly by using the primers described by Hutson et al. (12), a Dye-Dideoxy terminator cycle sequencing kit (Applied Biosystems, Inc., Foster City, Calif.), and a model 373A automatic DNA sequencer (Applied Biosystems, Inc.).

Phylogenetic analysis of the sequence data. Phylogenetic analyses were performed with the Genetics Computer Group package (4) and the PHYLIP phylogeny inference package (6). Reference 16S rRNA sequences were retrieved from the EMBL and GenBank data libraries and were aligned with the newly determined sequences by using the program PILEUP (4). The rRNA alignment was corrected manually, and approximately 100 bases at the $5^{\prime}$ end of the molecule were omitted from further analyses because of alignment uncertainties A distance matrix was calculated with the programs PRETTY (4) and DNADIST (6) by using the Kimura- 2 parameter, and a phylogenetic tree based on neighborjoining method data was constructed by using the program NEIGHBOR (6). The stability of the groups was ascertained by performing a bootstrap analysis (500 replications) with the programs DNABOOT, DNADIST, NEIGHBOR, and CONSENSE (6).

Nucleotide sequence accession numbers. The 16S rRNA gene sequences of $P$. harei DSM $10020^{\mathrm{T}}, P$. ivorii DSM $10022^{\mathrm{T}}$, and P. octavius NCTC $9810^{\mathrm{T}}$ have been deposited in the EMBL data library under accession numbers Y07839, Y07840, and Y07841, respectively.

\section{RESULTS AND DISCUSSION}

In a study of peptostreptococci isolated at St. Bartholomew's Hospital in London, United Kingdom (19), 256 strains from human clinical material were investigated, of which $22 \%$ could not be assigned to previously recognized species. Therefore, 127 strains (101 clinical strains and 26 reference strains), most of which were from this study, were selected for an analysis of their whole-cell compositions by PyMS. Figure 1 shows the clustering of these strains. A group of nine strains formed a distinct cluster (designated PyMS cluster 18) which was separate from other peptostreptococci, including $P$. asaccharolyticus (Fig. 1, cluster 1). These nine strains exhibited biochemical similarities with typical strains of $P$. asaccharolyticus but were readily distinguished from all of the other peptostreptococcal strains studied. On the basis of the PyMS data, two representative strains from this cluster (strains DSM $10020^{\mathrm{T}}$ and DSM 10021) were selected for further study. A group of three strains, cluster 22, was readily separable from all other PyMS clusters, including the type strain of $P$. anaerobius, NCTC 11460 (cluster 25), to which it exhibited some phenotypic resemblance. However, the strains of cluster 22 produced a distinctive PEP (Table 2) and were unique in forming isovaleric acid as their terminal VFA. Strains DSM $10022^{\mathrm{T}}$ and DSM 10023 of cluster 22 were selected for further characterization. Four strains formed a homogeneous group, designated cluster 9 , which was distinct but was part of a compositionally similar

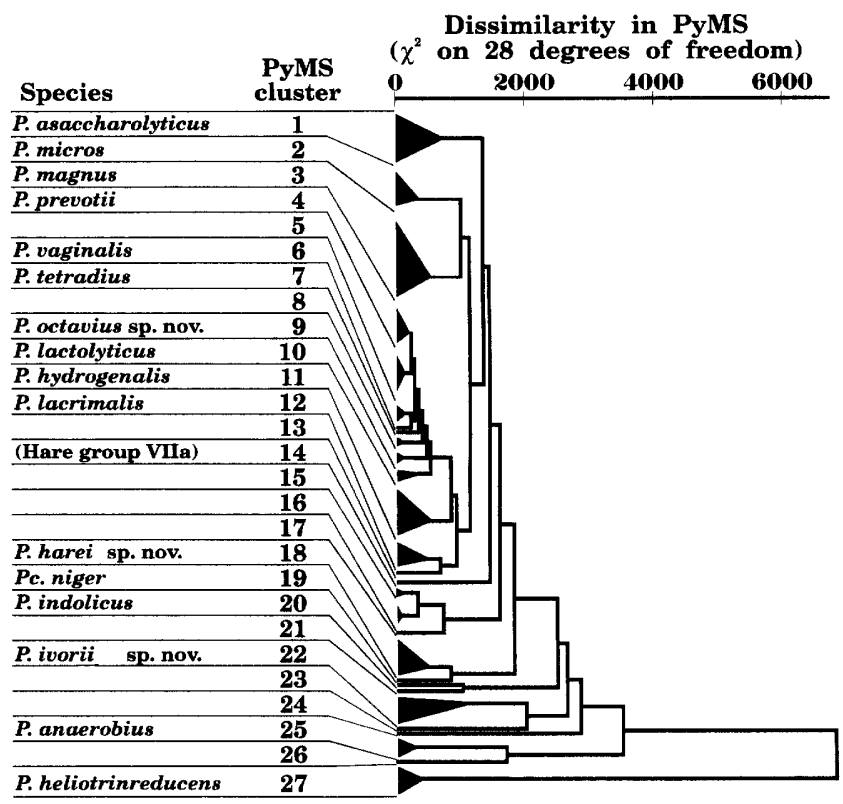

FIG. 1. Clustering of 26 reference and 101 clinical strains of gram-positive anaerobic cocci on the basis of whole-cell composition as assessed by PyMS. Numbered but unnamed clusters did not contain recognized type strains. Abbreviations: P., Peptostreptococcus; Pc., Peptococcus. 
complex of clusters (Fig. 1) containing the type strains of $P$. prevotii (cluster 4), Peptostreptococcus vaginalis (cluster 6), $P$. tetradius (cluster 7), Peptostreptococcus lactolyticus (cluster 10), and $P$. hydrogenalis (cluster 11). Although the separation of this group is visually less apparent on the dendrogram in Fig. 1 , an examination of the dissimilarity matrix, a Normix analysis, and identification analyses showed that cluster 9 was distinct. The four strains of cluster 9 exhibited a unique PEP and formed $n$-caproic acid as their terminal VFA (see below). Strains NCTC $9810^{\mathrm{T}}$, NCTC 9820, and DSM 10024 were typical of cluster 9 and were therefore selected for further analysis.

Biochemical characteristics of the seven strains selected from PyMS clusters 18, 22, and 9 and the type strains of previously recognized Peptostreptococcus species are shown in Table 2. The strains belonging to the clusters that were not selected for further biochemical and genetic analyses had biochemical reactions that were very similar to those of the strains chosen.

Strains DSM $10020^{\mathrm{T}}$ and DSM 10021 (PyMS cluster 18) were biochemically similar to $P$. asaccharolyticus NCTC $11461^{\mathrm{T}}$, but were easily distinguished by their cellular morphology and colonial morphology. The cells of PyMS cluster 18 strains were ovoid, stained strongly, and varied greatly in size and shape, in contrast to the very decolorized, regular cocci of $P$. asaccharolyticus strains. The colonies of PyMS cluster 18 strains were translucent and flat and grew very slowly compared to the yellowish, umbonate colonies of $P$. asaccharolyticus strains. Strains DSM $10022^{\mathrm{T}}$ and DSM 10023 (PyMS cluster 22) were readily distinguished from other peptostreptococci by their production of isovalerate as terminal VFA, their PEP, and their inability to ferment any of the carbohydrates tested. Strains NCTC $9810^{\mathrm{T}}$, NCTC 9820, and DSM 10024, members of Hare group VIII (PyMS cluster 9), resembled $P$. anaerobius NCTC $11460^{\mathrm{T}}$ in their ability to ferment carbohydrates, but were distinguished by the formation of $n$-caproate as terminal VFA and by the absence of the saccharolytic enzyme $\alpha$-glucosidase. The cells of PyMS cluster 9 strains were regularly coccoid, whereas the cells of most $P$. anaerobius strains are highly pleomorphic.

The DNA base compositions of representative strains of the three PyMS groups are shown in Table 2 . The values obtained ( 25 to $31 \mathrm{~mol} \%$ ) are in good agreement with the values reported by Huss et al. (11) but are low compared to the values for other members of the genus cited by Li et al. (14).

Representative strains of PyMS clusters 18, 22, and 9 were phylogenetically characterized by performing a partial $16 \mathrm{~S}$ rRNA gene sequence analysis. Approximately 1,480 bases of the 16S rRNAs of representative strains of PyMS cluster 18 $\left(\right.$ DSM $10020^{\mathrm{T}}$ ) and PyMS cluster 22 (DSM 10022 $2^{\mathrm{T}}$ ) were sequenced. Partial 16S rRNA sequences (approximately 450 bases, including variable regions V1 to V3) of strains DSM 10021 and DSM 10023 demonstrated that these organisms are phylogenetically highly related (level of $16 \mathrm{~S}$ rRNA sequence similarity, $100 \%$ ) to strains DSM $10020^{\mathrm{T}}$ and DSM $10022^{\mathrm{T}}$, respectively. Approximately 1,400 nucleotides of the $16 \mathrm{~S}$ rRNA of strain NCTC $9810^{\mathrm{T}}$ (PyMS cluster 9) were determined. The sequences of short fragments (approximately 600 bases) proximal to the $5^{\prime}$ end of the $16 \mathrm{~S}$ rRNA (including variable regions $\mathrm{V} 1$ to $\mathrm{V} 3$ ) of strains NCTC 9820 and DSM 10024 were found to be identical to the sequence of strain NCTC $9810^{\mathrm{T}}$, which demonstrated the genotypic homogeneity of PyMS cluster 9. Preliminary phylogenetic searches revealed that the newly determined sequences were related to the sequence of Clostridium rRNA cluster XIII (2), which includes most previously described Peptostreptococcus species. A de- tailed phylogenetic analysis was therefore performed with all members of this cluster together with representatives of Clostridium rRNA clusters XI and XIVa, which include $P$. anaerobius and $P$. productus, respectively. Figure 2 is a tree which shows the phylogenetic affinities of strains NCTC $9810^{\mathrm{T}}$, DSM $10020^{\mathrm{T}}$, and DSM $10022^{\mathrm{T}}$ based on a comparison of approximately 1,330 bases. It was evident from the treeing analysis and the sequence divergence values (Table 3 ) that the three representative strains of PyMS clusters 18, 22, and 9 constitute three separate sublines within Clostridium rRNA cluster XIII.

Two strains of PyMS cluster 18 (DSM $10020^{\mathrm{T}}$ and DSM 10021) exhibited considerable phylogenetic divergence (approximately 11\%) (Table 3 ) from the phenotypically similar organism $P$. asaccharolyticus. The nearest relative of PyMS cluster 18 is Peptostreptococcus lacrimalis, but a sequence divergence value of more than $8 \%$ clearly demonstrates that strains DSM $10020^{\mathrm{T}}$ and DSM 10021 represent a species different from $P$. lacrimalis. The two representative strains of PyMS cluster 22 (DSM 10022 $2^{\mathbf{T}}$ and DSM 10023) were phylogenetically distinct and exhibited more than $10 \%$ sequence divergence from previously recognized species of peptostreptococci. These data, in conjunction with the biochemical distinctiveness of the organisms (Table 4), demonstrate that the PyMS cluster 22 strains represent a new peptostreptococcal lineage. Strains NCTC $9810^{\mathrm{T}}$ and NCTC 9820 correspond to what was previously designated Hare group VIII. In addition, strain DSM 10024 was also found to be a member of this group. The phylogenetic analysis demonstrated that these strains (PyMS cluster 9) are members of a small peptostreptococcal rRNA subcluster which also includes $P$. hydrogenalis, $P$. lactolyticus, $P$. prevotii, $P$. tetradius, and $P$. vaginalis (Fig. 2 ). Although the association of PyMS cluster 9 strains with these peptostreptococcal species was statistically significant, sequence divergence values of 5.2 to $8.3 \%$ (Table 3 ) clearly show that this group represents a new species.

Based on the results of the present study, we believe that strains belonging to PyMS clusters 18, 22, and 9 form three phylogenetically distinct lineages that are worthy of species status. The names Peptostreptococcus harei (for strains of PyMS cluster 18), Peptostreptococcus ivorii (for strains of PyMS cluster 22), and Peptostreptococcus octavius (for strains of PyMS cluster 9) are therefore proposed. The species descriptions below are based on characteristics of the strains selected for genetic analysis (Table 1). We recognize that the new taxa, along with all other species of peptostreptococci, are phylogenetically far removed from the type species of the genus, $P$. anaerobius. However, we feel that at present it would be premature to recommend a major taxonomic restructuring of the genus. Assignment of the three new species to the genus Peptostreptococcus is, in our opinion, phenotypically the most appropriate at present. However, we recognize that this assignment is a placement of convenience which in the future may require emendation as the taxonomy of the group is revised.

Description of Peptostreptococcus harei sp. nov. Peptostreptococcus harei (ha're.i., M. L. gen. n. harei, of Hare, a British microbiologist). Cells are strictly anaerobic, gram-positive cocci that vary considerably in size (diameter, 0.5 to $1.5 \mu \mathrm{m}$ ) and shape (circular, oval, or elliptical). Colonies on sheep blood agar are less than $1 \mathrm{~mm}$ in diameter after incubation for $48 \mathrm{~h}$; after 5 days, they are approximately $1 \mathrm{~mm}$ in diameter, entire, flat, translucent, and nonhemolytic. Urease, ALP, coagulase, and $\mathrm{ADH}$ are not produced. Nitrate is not reduced. Indole and catalase production are variable. Acid is not formed from glucose, lactose, maltose, sucrose, raffinose, trehalose, sorbitol, cellobiose, arabinose, ribose, mannose, or mannitol. Acid formation from fructose is variable (one of the 
TABLE 2. Biochemical characteristics and DNA base contents of $P$. harei, $P$. ivorii, $P$. octavius, and reference peptostreptococcal strains ${ }^{a}$

\begin{tabular}{|c|c|c|c|c|c|c|c|c|c|c|c|c|c|c|c|c|c|c|c|c|c|c|c|c|c|c|c|c|c|}
\hline \multirow[b]{2}{*}{ Species } & \multirow[b]{2}{*}{ Strain } & \multirow{2}{*}{$\begin{array}{c}\mathrm{G}+\mathrm{C} \\
\text { content } \\
(\mathrm{mol} \%)\end{array}$} & \multirow{2}{*}{$\begin{array}{c}\text { Terminal } \\
\text { major } \\
\text { VFA }\end{array}$} & \multicolumn{6}{|c|}{ Production of: } & \multirow{2}{*}{$\begin{array}{l}\text { Nitrate } \\
\text { reduc- } \\
\text { tion }\end{array}$} & \multicolumn{8}{|c|}{ Carbohydrate fermentation reactions } & \multicolumn{5}{|c|}{ Saccharolytic enzymes } & \multicolumn{6}{|c|}{ Proteolytic enzymes } \\
\hline & & & & Indole & Urease & ALP & $\begin{array}{c}\text { Coagu- } \\
\text { lase }\end{array}$ & $\begin{array}{l}\text { Cata- } \\
\text { lase }\end{array}$ & $\mathrm{ADH}$ & & $\begin{array}{l}\text { Glu- } \\
\text { cose }\end{array}$ & $\begin{array}{l}\text { Lac- } \\
\text { tose }\end{array}$ & $\begin{array}{l}\text { Mal- } \\
\text { tose }\end{array}$ & $\begin{array}{c}\text { Su- } \\
\text { crose }\end{array}$ & $\begin{array}{l}\text { Fruc- } \\
\text { tose }\end{array}$ & $\begin{array}{l}\text { Raffi- } \\
\text { nose }\end{array}$ & $\begin{array}{l}\text { Ri- } \\
\text { bose }\end{array}$ & $\begin{array}{l}\text { Man- } \\
\text { nose }\end{array}$ & aGAL & bGAL & bGP & aGLU & J bGUR & $\operatorname{ArgA}$ & ProA & LeuA & PyrA & TyrA & HisA \\
\hline $\begin{array}{l}\text { P. asaccharo- } \\
\text { lyticus }\end{array}$ & NCTC $11461^{\mathrm{T}}$ & $\mathrm{ND}^{b}$ & B & $t^{c}$ & - & - & - & - & + & - & - & - & - & - & - & - & - & - & - & - & - & - & - & + & - & - & - & - & $\mathrm{w}$ \\
\hline $\begin{array}{l}\text { P. harei } \\
\text { sp. nov. }\end{array}$ & DSM $10020^{\mathrm{T}}$ & 25 & B & - & - & - & - & + & - & - & - & - & - & - & - & - & - & - & - & - & - & - & - & + & - & w & - & + & + \\
\hline $\begin{array}{l}\text { P. harei } \\
\text { sp. nov. }\end{array}$ & DSM 10021 & ND & B & w & - & - & - & + & - & - & - & - & - & - & + & - & - & - & - & - & - & - & - & + & - & - & - & $\mathrm{w}$ & $\mathrm{w}$ \\
\hline$P$. indolicus & NCTC $11088^{\mathrm{T}}$ & ND & B & + & - & + & + & - & - & - & - & - & - & - & - & - & - & - & - & - & - & - & - & + & - & - & - & + & + \\
\hline P. hydrogenalis & DSM $7454^{\mathrm{T}}$ & ND & B & + & - & - & - & - & - & - & + & + & + & + & + & + & - & t & - & - & - & + & - & - & - & - & - & - & - \\
\hline P. lacrimalis & DSM $7455^{\mathrm{T}}$ & ND & B & - & - & - & - & - & - & - & - & - & - & - & - & - & - & - & - & - & - & - & - & w & - & + & - & - & - \\
\hline P. lactolyticus & DSM $7456^{\mathrm{T}}$ & ND & B & - & + & - & - & - & - & - & + & + & + & - & + & - & - & + & - & + & + & - & - & + & - & - & - & - & - \\
\hline P. vaginalis & DSM $7457^{\mathrm{T}}$ & ND & B & - & - & $\mathrm{w}$ & - & $\mathrm{w}$ & + & - & + & - & + & - & + & - & - & w & - & - & - & - & - & + & - & + & - & - & + \\
\hline P. prevotii & NCTC $11806^{\mathrm{T}}$ & ND & B & - & + & - & - & + & - & + & - & - & - & - & + & + & + & + & + & - & - & + & + & + & - & - & + & w & + \\
\hline P. tetradius & DSM $2951^{\mathrm{T}}$ & ND & B & - & + & - & - & - & - & - & + & - & + & + & + & + & - & + & - & - & - & + & + & $\mathrm{w}$ & - & - & - & - & w \\
\hline $\begin{array}{l}P . \text { ivorii } \\
\text { sp. nov. }\end{array}$ & DSM $10022^{\mathrm{T}}$ & 29 & IV & - & - & - & - & - & - & - & - & - & - & - & - & - & - & - & - & - & - & - & - & - & + & - & - & - & - \\
\hline $\begin{array}{l}P . \text { ivorii } \\
\text { sp. nov. }\end{array}$ & DSM 10023 & ND & IV & - & - & - & - & + & - & - & - & - & - & - & - & - & - & - & - & - & - & - & - & - & + & - & - & - & - \\
\hline P. anaerobius & NCTC $11460^{\mathrm{T}}$ & ND & IC & - & - & - & - & - & - & - & + & - & + & - & + & - & - & + & - & - & - & - & - & - & + & - & - & - & - \\
\hline $\begin{array}{l}P . \text { octavius } \\
\text { sp. nov. }\end{array}$ & NCTC $9810^{\mathrm{T}}$ & 28 & $\mathrm{C}$ & - & - & - & - & - & - & - & + & - & - & - & + & - & + & + & - & - & - & - & - & - & + & - & $\mathrm{w}$ & - & - \\
\hline $\begin{array}{l}P . \text { octavius } \\
\text { sp. nov. }\end{array}$ & NCTC 9820 & 26 & $\mathrm{C}$ & - & - & - & - & w & - & - & + & - & - & - & + & - & + & + & - & - & - & - & - & - & + & - & $\mathrm{w}$ & - & - \\
\hline $\begin{array}{l}\text { P. octavius } \\
\text { sp. nov. }\end{array}$ & DSM 10024 & 31 & C & - & - & - & - & w & - & - & w & - & $\mathrm{w}$ & w & + & - & + & + & - & - & - & - & - & - & + & - & $\mathrm{w}$ & - & - \\
\hline
\end{tabular}

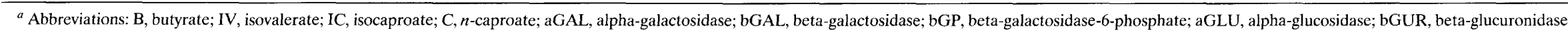
ArgA, arginine AMD; ProA, proline AMD; LeuA, leucine AMD; PyrA, pyroglutamate AMD; TyrA, tyrosine AMD; HisA, histidine AMD.

$\mathrm{N}$, not determined.

$c+$, positive $(\mathrm{pH}<5.5) ;-$, negative $(\mathrm{pH}>6.0)$; w, weakly positive ( $\mathrm{pH} 5.5$ to 6.0 ). 


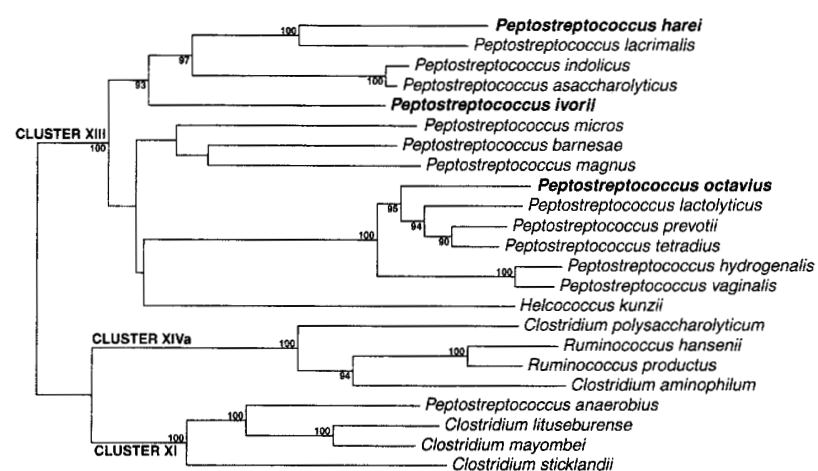

FIG. 2. Phylogenetic tree constructed by using the neighbor-joining method, showing the positions of $P$. harei sp. nov., $P$. ivorii sp. nov., $P$. octavius $\mathrm{sp}$. nov., and other Peptostreptococcus species belonging to Clostridium rRNA clusters XI, XIII, and XIVa (2). Significant bootstrap values (90\% or more), expressed as percentages based on 500 replications, are indicated at the branch points.

two strains examined is positive). When the ATB 32A preformed enzyme system (API-BioMerieux) is used, the proteolytic enzyme arginine arylamidase (AMD) is present, but saccharolytic enzymes are not detected; production of the enzymes leucine AMD, tyrosine AMD, and histidine AMD is variable. The major VFAs produced in Robertson's cooked meat broth are acetic acid and butyric acid, and smaller quantities of propionic, isovaleric, and $n$-valeric acids are sometimes produced. $P$. harei has been isolated from antral washout specimens, pus from the peritoneal cavity, infected sacral sores, and abscesses of the face, neck, breast, and thigh, occasionally in pure culture (20). The type strain, DSM 10020, was isolated from pus from an infected sacral sore of a diabetic patient; it was cocultured with Peptostreptococcus magnus, Enterococcus spp., and Prevotella melaninogenica. Strain DSM $10020^{\mathrm{T}}$ forms catalase but does not form indole or acid from fructose; the proteolytic enzymes leucine AMD, tyrosine AMD, and histidine AMD are present. The $\mathrm{G}+\mathrm{C}$ content of the DNA of strain DSM $10020^{\mathrm{T}}$ is $25 \mathrm{~mol} \%$.
Description of Peptostreptococcus ivorii sp. nov. Peptostreptococcus ivorii (i.vo'ri.i. M. L. gen. n. ivorii, of Ivor, a British microbiologist who first isolated the organism). Cells are strictly anaerobic, gram-positive cocci which vary in size (diameter, 0.4 to $1.5 \mu \mathrm{m}$ ) and occur in clumps. Colonies on sheep blood agar are tiny after incubation for $48 \mathrm{~h}$ but by 5 days are 1 to $2 \mathrm{~mm}$ in diameter, yellow-white, low convex, entire, circular, and nonhemolytic. Indole, urease, ALP, coagulase, and $\mathrm{ADH}$ are not produced. Nitrate is not reduced. Catalase production is variable. Acid is not produced from glucose, lactose, maltose, sucrose, fructose, raffinose, trehalose, sorbitol, cellobiose, arabinose, ribose, mannose, or mannitol. When the ATB $32 \mathrm{~A}$ preformed enzyme system (API-BioMerieux) is used, saccharolytic enzymes are not detected, and proline AMD is the only proteolytic enzyme formed. The major VFAs produced in Robertson's cooked meat broth are butyric and isovaleric acids, and smaller, variable quantities of acetic, propionic, isobutyric, and $n$-valeric acids are also produced. $P$. ivorii has been isolated from a leg ulcer, a preputial sac, and an intrauterine contraceptive device (20). The type strain, DSM 10022, was isolated from a leg ulcer; it was cocultured with $P$. magnus, Klebsiella oxytoca, and Bacteroides ureolyticus. Strain DSM $10022^{\mathrm{T}}$ does not form catalase. The $\mathrm{G}+\mathrm{C}$ content of the DNA of strain DSM $10022^{\mathrm{T}}$ is $29 \mathrm{~mol} \%$.

Description of Peptostreptococcus octavius sp. nov. Peptostreptococcus octavius (oc.ta'vi.us. L. adj. octavius, eighth, referring to the fact that the organism was previously assigned to Hare group VIII). Cells are strictly anaerobic, gram-positive cocci (diameter, 0.7 to $0.9 \mu \mathrm{m}$ ) that occur in clumps. Colonies on sheep blood agar are less than $1 \mathrm{~mm}$ in diameter after incubation for $48 \mathrm{~h}$; after 5 days, they are 1 to $2 \mathrm{~mm}$ in diameter, yellow-white, glistening, circular, entire, and nonhemolytic. Indole, urease, ALP, coagulase, and ADH are not produced. Nitrate is not reduced. Catalase production is variable. Acid is produced from glucose, fructose, ribose, and mannose, but not from lactose, raffinose, trehalose, cellobiose, or arabinose. Acid production from maltose, sucrose, sorbitol, and mannitol is variable. The proteolytic enzymes proline AMD and pyroglutamyl AMD are produced as determined with the ATB 32A

TABLE 3. Levels of sequence divergence of 16S rRNA genes of Peptostreptococcus species

\begin{tabular}{|c|c|c|c|c|c|c|c|c|c|c|c|c|c|c|c|}
\hline \multirow[b]{2}{*}{ Species $^{a}$} & \multicolumn{15}{|c|}{$\%$ Sequence divergence } \\
\hline & 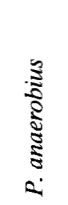 & 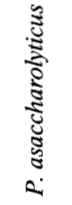 & 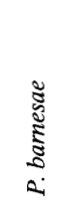 & $\frac{\tilde{z}}{\tilde{s}}$ & 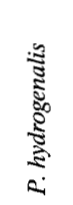 & 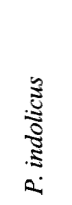 & $\begin{array}{l}: \bar{z} \\
\vdots \\
:\end{array}$ & 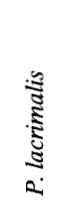 & 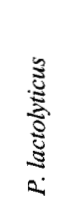 & 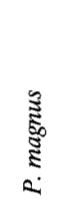 & 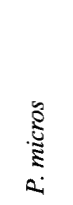 & 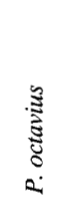 & 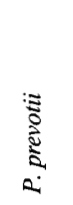 & 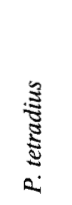 & 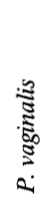 \\
\hline P. asaccharolyticus & 16.3 & & & & & & & & & & & & & & \\
\hline P. barnesae & 17.6 & 12.4 & & & & & & & & & & & & & \\
\hline$P$. harei & 18.0 & 11.0 & 14.8 & & & & & & & & & & & & \\
\hline P. hydrogenalis & 18.6 & 15.6 & 15.0 & 15.2 & & & & & & & & & & & \\
\hline P. indolicus & 16.5 & 1.0 & 12.7 & 11.6 & 16.0 & & & & & & & & & & \\
\hline P. ivorii & 17.2 & 10.7 & 11.4 & 13.5 & 17.6 & 10.8 & & & & & & & & & \\
\hline$P$. lacrimalis & 18.1 & 10.9 & 13.9 & 8.4 & 16.4 & 11.2 & 12.3 & & & & & & & & \\
\hline P. lactolyticus & 19.9 & 14.4 & 14.3 & 15.1 & 7.9 & 14.4 & 15.5 & 15.0 & & & & & & & \\
\hline P. magnus & 17.4 & 11.9 & 9.2 & 14.2 & 14.7 & 12.1 & 13.2 & 15.0 & 15.6 & & & & & & \\
\hline P. micros & 17.8 & 12.7 & 10.6 & 15.6 & 15.7 & 12.9 & 12.2 & 15.6 & 15.9 & 11.0 & & & & & \\
\hline P. octavius & 19.0 & 15.7 & 14.3 & 16.2 & 8.3 & 15.7 & 15.3 & 15.3 & 6.3 & 15.8 & 15.8 & & & & \\
\hline P. prevotii & 18.8 & 14.0 & 14.0 & 14.7 & 7.8 & 14.3 & 15.3 & 15.3 & 4.8 & 15.4 & 15.3 & 5.6 & & & \\
\hline$P$. tetradius & 18.4 & 14.5 & 13.8 & 14.6 & 7.3 & 14.8 & 15.1 & 14.4 & 3.8 & 15.7 & 15.2 & 5.2 & 2.5 & & \\
\hline$P$. vaginalis & 19.0 & 15.4 & 15.5 & 16.1 & 2.2 & 15.7 & 17.1 & 16.3 & 7.4 & 15.1 & 15.4 & 7.8 & 7.3 & 6.9 & \\
\hline H. kunzii & 18.4 & 15.3 & 14.4 & 18.0 & 17.1 & 15.4 & 15.6 & 16.6 & 16.3 & 13.8 & 15.3 & 16.2 & 16.3 & 16.3 & 7.6 \\
\hline
\end{tabular}

${ }^{a}$ P., Peptostreptococcus; H., Helcococcus. 


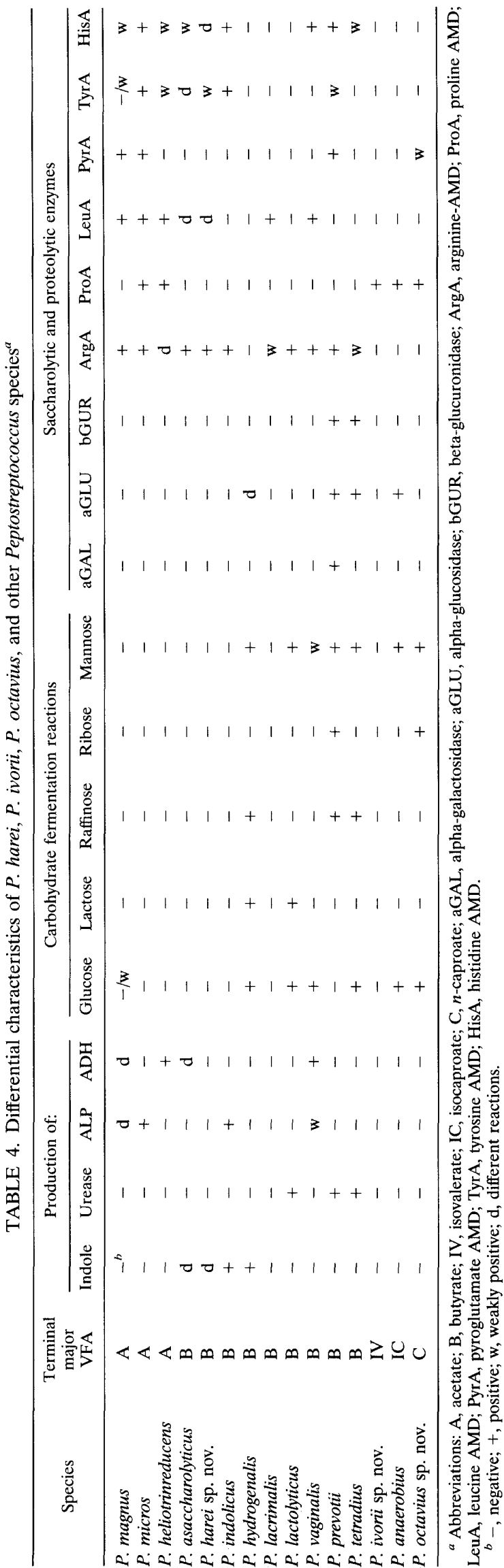

preformed enzyme system (API-BioMerieux), but saccharolytic enzymes are not detected. The major VFAs produced in Robertson's cooked meat broth are butyric, isovaleric, and $n$-caproic acids. $P$. octavius has been isolated from intranasal specimens, skin, and normal vaginal flora $(20,24)$. The type strain, NCTC 9810, was isolated from normal nasal flora. Strain NCTC $9810^{\mathrm{T}}$ does not form catalase; weak acid is produced from sorbitol but not from maltose, mannitol, or sucrose. The $\mathrm{G}+\mathrm{C}$ content of the DNA of strain NCTC $9810^{\mathrm{T}}$ is $28 \mathrm{~mol} \%$.

\section{ACKNOWLEDGMENTS}

We gratefully acknowledge the assistance of $\mathrm{M}$. Corion of The London Hospital Medical College, the staff of the Department of Medical Microbiology, St. Bartholomew's Hospital, London, and the staff of the Department of Medical Microbiology, Southmead Hospital, Bristol. This work was supported by grants from the Showering Fund, Bristol, the Sir Jules Thorn Charitable Trust, and the European Community (grants Bio-2-CT93-019 and CHRX-CT93-0194).

\section{REFERENCES}

1. Anonymous. 1988. SPSS-PC user's guide. SPSS, Inc., Chicago, Ill.

2. Collins, M. D., P. A. Lawson, A. Willems, J. J. Cordoba, J. FernandezGarayzabal, P. Garcia, J. Cai, H. Hippe, and J. A. E. Farrow. 1994. The phylogeny of the genus Clostridium: proposal of five new genera and eleven new species combinations. Int. J. Syst. Bacteriol. 44:812-826.

3. Cowan, S. T. 1974. Cowan \& Steel's manual for the identification of medical bacteria, 2nd ed. Cambridge University Press, Cambridge, United Kingdom.

4. Devereux, J., P. Haeberli, and D. Smithies. 1984. A comprehensive set of sequence analysis programs for the VAX. Nucleic Acids Res. 12:387-395.

5. Ezaki, T., H. Oyaizu, and E. Yabuuchi. 1992. The anaerobic gram-positive cocci, p. 1879-1892. In A. Balows, H. G. Truper, M. Dworkin, W. Harder and K. H. Schleifer (ed.), The prokaryotes, 2nd ed. Springer-Verlag, New York, N.Y.

6. Felsenstein, J. 1989. PHYLIP — phylogeny inference package (version 3.2). Cladistics 5:164-166.

7. Garvie, E. I. 1976. Hybridization between the deoxyribonucleic acid of some strains of heterofermentative lactic acid bacteria. Int. J. Syst. Bacteriol. 26:116-122.

8. Gutteridge, C. S., L. Vallis, and H. J. H. MacFie. 1985. Numerical methods in the classification of micro-organisms by pyrolysis mass spectrometry, $\mathrm{p}$ 369-401. In M. Goodfellow, D. Jones, and F. G. Priest (ed.), Computerassisted bacterial systematics. Academic Press, London, United Kingdom.

9. Harpold, D. J., and B. L. Wasilauskas. 1987. Rapid identification of obligately anaerobic gram-positive cocci using high-pressure liquid chromatography. J. Clin. Microbiol. 25:996-1001.

10. Holdeman Moore, L. V., J. L. Johnson, and W. E. C. Moore. 1986. Genus Peptococcus and genus Peptostreptococcus, p. 1082-1092. In P. H. A. Sneath, N. S. Mair, M. E. Sharpe, and J. G. Holt (ed.), Bergey's manual of systematic bacteriology, vol. 2. Williams and Wilkins, Baltimore, Md.

11. Huss, V. A. R., H. Festl, and K. H. Schleifer. 1984. Nucleic acid hybridization studies and deoxyribonucleic acid base compositions of anaerobic grampositive cocci. Int. J. Syst. Bacteriol. 34:95-101.

12. Hutson, R. A., D. E. Thompson, and M. D. Collins. 1993. Genetic interrelationships of saccharolytic Clostridium botulinum types B, E and F and related clostridia as revealed by small-subunit rRNA gene sequences. FEMS Microbiol. Lett. 108:103-110.

13. Lawson, P. A., S. E. Gharbia, H. N. Shah, and D. R. Clark. 1989. Recognition of Fusobacterium nucleatum subgroups $\mathrm{Fn}-1$, Fn-2 and $\mathrm{Fn}-3$ by ribosomal RNA gene restriction patterns. FEMS Microbiol. Lett. 65:41-46.

14. Li, N., Y. Hashimoto, S. Adnan, H. Miura, H. Yamamoto, and T. Ezaki. 1992 Three new species of the genus Peptostreptococcus isolated from humans: Peptostreptococcus vaginalis sp. nov., Peptostreptococcus lacrimalis $\mathrm{sp}$. nov., and Peptostreptococcus lactolyticus sp. nov. Int. J. Syst. Bacteriol. 42:602-605.

15. Li, N., Y. Hashimoto, and T. Ezaki. 1994. Determination of 16S ribosomal RNA sequences of all members of the genus Peptostreptococcus and their phylogenetic position. FEMS Microbiol. Lett. 116:1-6.

16. Magee, J. T. 1993. Whole organism fingerprinting, p. 383-427. In M. Good fellow and A. G. O'Donnell (ed.), Handbook of new bacterial systematics. Academic Press, London, United Kingdom.

17. Magee, J. T. 1994. Analytical fingerprinting methods, p. 523-553. In M Goodfellow and A. G. O'Donnell (ed.), Chemical methods in prokaryotic systematics. John Wiley \& Sons, Chichester, United Kingdom.

18. Murdoch, D. A., and J. T. Magee. 1995. A numerical taxonomic study of the gram-positive anaerobic cocci. J. Med. Microbiol. 43:148-155.

19. Murdoch, D. A., and I. J. Mitchelmore. 1991. The laboratory identification of gram-positive anaerobic cocci. J. Med. Microbiol. 34:295-308. 
20. Murdoch, D. A., I. J. Mitchelmore, and S. Tabaqchali. 1994. The clinical importance of gram-positive anaerobic cocci isolated at St Bartholomew's Hospital, London, in 1987. J. Med. Microbiol. 41:36-44.

21. Owen, R. J., and L. R. Hill. 1979. The estimation of base compositions, base pairing and genome sizes of bacterial deoxyribonucleic acids. Soc. Appl. Bacteriol. Tech. Ser. 14:277-296.

22. Paster, B. J., J. B. Russell, C. M. J. Yang, J. M. Chow, C. R. Woese, and R. Tanner. 1993. Phylogeny of the ammonia-producing ruminal bacteria Peptostreptococcus anaerobius, Clostridium sticklandii, and Clostridium aminophi- lum sp. nov. Int. J. Syst. Bacteriol. 43:107-110.

23. Taylor, E. A., P. J. H. Jackman, and I. Phillips. 1991. The differentiation of asaccharolytic anaerobic gram-positive cocci by protein electrophoresis. J. Med. Microbiol. 34:339-348.

24. Thomas, C. G. A., and R. Hare. 1954. The classification of anaerobic cocci and their isolation in normal human beings and pathological processes. J. Clin. Pathol. 7:300-304.

25. Wishart, D. 1987. Clustan user's manual, 4th ed. Clustan, Ltd., Edinburgh, United Kingdom. 